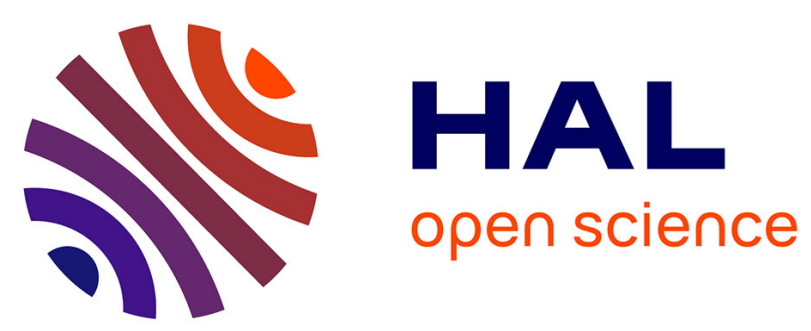

\title{
Robust bifunctional buckypapers from carbon nanotubes and polynorbornene copolymers for flexible engineering of enzymatic bioelectrodes
}

Andrew Gross, Mathew P. Robin, Yannig Nédellec, Rachel K. O’reilly, Dan Shan, Serge Cosnier

\section{To cite this version:}

Andrew Gross, Mathew P. Robin, Yannig Nédellec, Rachel K. O'reilly, Dan Shan, et al.. Robust bifunctional buckypapers from carbon nanotubes and polynorbornene copolymers for flexible engineering of enzymatic bioelectrodes. Carbon, 2016, 107, pp.542 - 547. 10.1016/j.carbon.2016.06.027 . hal-01644744

\author{
HAL Id: hal-01644744 \\ https://hal.science/hal-01644744
}

Submitted on 19 Nov 2020

HAL is a multi-disciplinary open access archive for the deposit and dissemination of scientific research documents, whether they are published or not. The documents may come from teaching and research institutions in France or abroad, or from public or private research centers.
L'archive ouverte pluridisciplinaire HAL, est destinée au dépôt et à la diffusion de documents scientifiques de niveau recherche, publiés ou non, émanant des établissements d'enseignement et de recherche français ou étrangers, des laboratoires publics ou privés. 
$12^{\text {th }}$ April 2016

\section{Robust Bifunctional Buckypapers from Carbon Nanotubes and Polynorbornene Copolymers for Flexible Engineering of Enzymatic Bioelectrodes}

Andrew J. Gross ${ }^{\dagger}$, Mathew P. Robin ${ }^{\star}$, Yannig Nedellec ${ }^{\dagger}$, Rachel K. O’Reilly ${ }^{\ddagger}$, Dan Shan ${ }^{\S}$ and Serge Cosnier $^{\dagger *}$

${ }^{\dagger}$ Department of Molecular Chemistry, UMR 5250, University Grenoble Alps, 38000 Grenoble, France

* Department of Chemistry, University of Warwick, Gibbet Hill, Coventry CV4 7AL, United Kingdom

§ Sino-French Laboratory of Biomaterials and Bioanalytical Chemistry, School of Environmental and Biological Engineering, Nanjing University of Science and Technology, Nanjing 210094, China

1. Abstract

* Corresponding Author: Fax : +33 456-520805. Email : serge.cosnier@ujf-grenoble.fr 
Enzymatic biofuel cells offer the exciting prospect of clean energy production for implantable devices, but such devices are still exotic and require improvements in electrode design and performance. Here a global strategy to prepare robust and versatile buckypaper bioelectrodes for advancing biofuel cell applications is presented. The fabrication method is based on a combination of original bifunctional polynorbornene copolymers with carbon nanotubes. Use of copolymers containing both pyrene and activated ester groups for cross-linking and tethering, respectively, increases the mechanical and electrochemical performance compared to buckypaper prepared without polymer or with the pyrene homopolymer. The amount of polymer used is an important parameter and was optimized to improve mechanical performance. High surface concentrations of reactive ester functionalities were obtained using long-chain polymers and exhibited high selectivity for attachment of aminoanthraquinone and the enzyme laccase. High performance biocathodes for direct oxygen reduction were constructed by immobilization of laccase on unmodified and anthraquinone-modified buckypapers. Anthraquinonemodified electrodes gave increased current densities due to improved electrical wiring of laccase via the hydrophobic pocket near the laccase T1 site. Biocathode stability over one month was excellent $(53 \%$ current density after 24 days) and thus a new class of practical carbon-based enzymatic biofuels is envisioned.

\section{Introduction}

Enzymatic biofuel cells (EBFCs) offer great promise as low-power electricity sources for wearable and implantable bioelectronic devices from medical devices to environmental biosensors. [1-3] Tremendous advances have been made towards implantable fuel cells since the late 2000's and in particular for glucose EBFCs[2] where operation in vivo has been demonstrated, for example, in the retroperitoneal space of a rat[4] and in the body of a snail.[5] However, major technical challenges remain for implantable biofuel cells, including limited operational stability and modest power output at 
physiological pH.[6, 7] Key challenges in EBFC design are the development of electrodes which offer (i) stable immobilization of enzymes and mediators, (ii) electrical wiring with the active site of enzymes, (iii) efficient diffusional transport in the cell, and (iv) are lightweight and easily integrated into devices. Carbon nanotubes (CNTs) have great advantages as an electrode material for bioelectrodes due to their large surface area and exceptional electronic and mechanical properties which allow enhanced direct and mediated electron transfer.[8, 9] Carbon nanotube bioelectrodes can be prepared by drop casting,[10] spinning,[11] 3D printing[12] and direct growth[13] onto a conductive support, by mechanical compression into free-standing disks,[8] or by filtration to give free-standing or supported thin films (buckypaper, BP).[14-16] BP bioelectrodes are commonly prepared on supporting substrates, such as Toray paper, to improve stability and prevent nanotube release into the local environment.[17-19] Freestanding buckypaper tends to be brittle and difficult to manipulate but is desired for device integration and to minimize contact resistance and mass transport limitations. $[5,17,20]$ Free-standing BP has several advantages over other CNT materials: it is extremely thin, lightweight and flexible, no electrode support is required, and it is easily processed into different shapes and sizes.

Surface functionalization techniques are essential for the immobilization and stabilization of enzymes on electrodes for biofuel cell applications.[7] Among the few reports available, the best enzyme immobilization methods are adsorption,[8] encapsulation via Nafion[21] and hydrogel,[22] and via surface modification with pyrene derivatives. $[5,14,20]$ For example, the recent work by Bourourou et al. demonstrated functionalization of freestanding BP via bis-pyrene-2,2'-azino-bis(3ethylbenzothiazoline-6-sulfonic acid) as a simple and stable platform for enzyme wiring.[20] The presence of two pyrene groups on the molecule offered reinforcement of the buckypaper via nanotube cross-linking. However, the close proximity of the two pyrene groups leads to a low probability of connecting two CNTs. A more effective approach to improve cross-linking of CNTs is to incorporate long linear polymer chains presenting at least ten pyrene groups, although use of polymers requires 
careful attention to avoid poorly conducting materials that provide inefficient electron transfer and diffusional barriers.[15]

Here we report the optimization and preparation of a new class of reinforced free-standing buckypapers using multifunctional polynorbornenes. Use of the BP materials for coupling anthraquinone via amide bond formation is investigated and a biocathode for direct oxygen reduction via immobilised laccase from Trametes versicolor is demonstrated.

\section{Experimental Section}

\subsection{Materials and apparatus}

Mono-sodium phosphate monohydrate (98-102\%), di-sodium hydrogen phosphate heptahydrate (98$102 \%$ ), sulfuric acid (95-98\%), 2-aminoanthraquinone (technical grade), ethanol (EtOH, $\geq 99.8 \%$ ), $N, N$ dimethylformamide (DMF, 99.9\%) and laccase (13.6 $\mathrm{U} \mathrm{mg}^{-1}$ ) from Trametes versicolor were purchased from Sigma Aldrich and used as received. Dry solvents were used directly from a drying and degassing solvent tower delivery system. Aqueous solutions were prepared from ultrapure water at $25^{\circ} \mathrm{C}$ (resistivity $\geq 18.2 \mathrm{M} \Omega \mathrm{cm})$. Laccase was stored at $4{ }^{\circ} \mathrm{C}$. Commercial grade multi-walled carbon nanotubes (MWCNTs, $9.5 \mathrm{~nm}$ diameter, > 95\% purity) were obtained from Nanocyl and used as received without purification. High purity oxygen and argon were obtained from Messer. ${ }^{1} \mathrm{H}$ and ${ }^{13} \mathrm{C}$ NMR spectra were recorded on a Bruker DPX-400 or DRX-500 spectrometer in $\mathrm{CDCl}_{3}$ unless otherwise stated. Chemical shifts are given in ppm downfield from the internal standard tetramethylsilane. Size exclusion chromatography (SEC) measurements were conducted using a Varian 390-LC-Multi detector suite fitted with differential refractive index (DRI), and UV/Vis detectors. A guard column (Varian Polymer Laboratories PLGel $5 \mu \mathrm{m}, 50 \times 7.5 \mathrm{~mm}$ ) and two mixed D columns (Varian Polymer Laboratories PLGel $5 \mu \mathrm{m}, 300 \times 7.5 \mathrm{~mm}$ ) were used. The mobile phase was chloroform with $2 \%$ trimethylamine eluent at a 
flow rate of $1.0 \mathrm{ml} \cdot \mathrm{min}^{-1}$. SEC data was analysed using Cirrus v3.3 with calibration curves produced using Varian Polymer laboratories Easi-Vials linear poly(styrene) standards (162 Da - $240 \mathrm{kDa})$.

\subsection{Synthesis of polynorbornene homopolymer, random copolymers and block copolymers}

The polynorbornene homopolymer $\mathrm{P}\left(\mathrm{Py}_{50}\right)$ (1) was synthesized via ring opening metathesis polymerization (ROMP) of (1-pyrenyl)methyl exo-5-norbornene-2-carboxylate (PyNb) as previously reported.[15] The polynorbornene random copolymers $\mathrm{P}\left(\mathrm{Py}_{13}-c o-\mathrm{NHS}_{13}\right)(2)$ and $\mathrm{P}\left(\mathrm{Py}_{66}-c o-\mathrm{NHS} 66\right)(3)$ and block copolymers $\mathrm{P}\left(\mathrm{Py}_{6.5}-b-\mathrm{NHS}_{13}-b-\mathrm{Py}_{6.5}\right)$ (4) and $\mathrm{P}\left(\mathrm{Py}_{33}-b-\mathrm{NHS}_{66}-b-\mathrm{Py}_{33}\right)(5)$ were synthesized via ROMP from pyNb and $N$-(2,5-dioxopyrrolidin-1-yl octanoate)-cis-5-norbornene-exo-dicarboximide (NHSNb) as described in the Supporting Information.

\subsection{Preparation of polynorbornene buckypapers}

First, $150 \mathrm{mg}$ of MWCNTs were added into $50 \mathrm{~mL} \mathrm{DMF}$ and dispersed by sonication for $30 \mathrm{~min}$. Next, $6 \mathrm{mg}$ of polymer was added into $3 \mathrm{~mL} \mathrm{DMF}$ and dissolved by sonication for 5 mins. $10 \%$ polymer: $90 \%$ CNT solutions were prepared by mixing $1.81 \mathrm{~mL}$ of polymer solution and $10.9 \mathrm{~mL}$ of CNT solution. 20\% polymer: $80 \%$ CNT solutions were prepared by mixing $4.09 \mathrm{~mL}$ of polymer solution and $10.9 \mathrm{~mL}$ of MWCNT solution. 50\% polymer: $50 \%$ CNT solutions were prepared by mixing $16.35 \mathrm{~mL}$ of polymer solution and $10.9 \mathrm{~mL}$ of MWCNT solution. All solutions were mixed by sonication for $15 \mathrm{~min}$. The mixed solutions were subsequently passed through a Millipore PTFE filter (JHWP, $0.45 \mu \mathrm{M}, 46 \mathrm{~mm}$ diameter) under high vacuum and left for 2 hrs. The buckypaper coated filters were left to dry flat at room temperature in the presence of desiccant, and then cut to size using a scalpel. Buckypapers were prepared using $80 \% \mathrm{CNT}: 20 \%$ polymer in wt $\%$ solution unless otherwise stated.

\subsection{Electrochemistry}

Electrochemical measurements were performed at room temperature using an Eco Chemie Autloab PGSTAT 100 potentiostat running GPES 4.9 software. A conventional three-electrode cell set-up was used for all electrochemical experiments comprising a buckypaper working electrode, a $\mathrm{AgAgCl}$ (sat. 
$\mathrm{KCl})$ reference electrode and a Pt wire counter electrode. A small copper tape contact was added to the back of the buckypaper for electrical connection via a crocodile clip. Inter-electrode spacing was $\leq 0.5$ $\mathrm{cm}$. The surface area of the buckypaper electrodes was $0.46 \mathrm{~cm}^{2}$. Surface concentrations of electroactive groups were determined from equation S1 according to Faraday's law (equation S1) and electron transfer rate constants were estimated from equation S2 (see Supporting Information).

\subsection{Surface coupling reactions}

For anthraquinone coupling experiments, buckypapers were fully immersed in $2 \mathrm{mM} 2$ aminoanthraquinone in EtOH with stirring. Buckypapers were subsequently rinsed with EtOH and acetone then sonicated in $\mathrm{EtOH}$ for $1 \mathrm{~min}$. For laccase coupling experiments, $5 \mathrm{mg} / \mathrm{mL}$ laccase was prepared in $0.1 \mathrm{M} \mathrm{PB} \mathrm{pH} 5$ and incubated on the buckypaper substrate $(25 \mu \mathrm{L})$ for $1 \mathrm{hr}$ at $4^{\circ} \mathrm{C}$, then then thoroughly rinsed with PB before use. Laccase-modified electrodes were stored in $0.1 \mathrm{M} \mathrm{PB}$ pH 5 before and after use.

\subsection{Mechanical properties and surface characterization}

Tensile modulus and strength were measured using a Shimadzu AGS-X with a cross-head speed of 5 $\mu \mathrm{m} / \mathrm{sec}$ and a $20 \mathrm{~N}$ load cell. Sample dimensions were width $=20 \mathrm{~mm}$, length $=30 \mathrm{~mm}$ and a specified thickness in the range $=0.08-0.2 \mathrm{~mm}$. Calibration length was $10 \mathrm{~mm}$ between grips. Tensile modulus was obtained from the linear part of the stress/strain plot. Tensile strength was measured as the maximum stress point before failure.

Static water contact angles were obtained at room temperature by delivering a $5 \mu \mathrm{L}$ droplet of ultrapure water onto the surface of a sample on a horizontal stage using a DataPhysics OCA 35 contact angle system. 5 measurements were recorded per sample from a minimum of 2 independent samples. 
Buckypaper conductivities were measured using a Keithley 2450 sourcemeter with an S-302-4 mounting stand and SP4 four-point probe head. 4 measurements were recorded per sample from a minimum of 2 independent samples.

\section{Results and Discussion}

A series of five polynorbornenes (Figure 1A) was synthesized by ROMP (see Supporting Information): a pyrene homopolymer $\mathbf{1}$, bifunctional random copolymers with different lengths $\mathbf{2}, \mathbf{3}$ and A-B-A triblock copolymers with different lengths $\mathbf{4}, \mathbf{5}$. The CNT-based polynorbornene BP electrodes with thicknesses in the range $85-200 \mu \mathrm{m}(n=23)$ were prepared in several steps (see Figure 1B and Experimental Section).

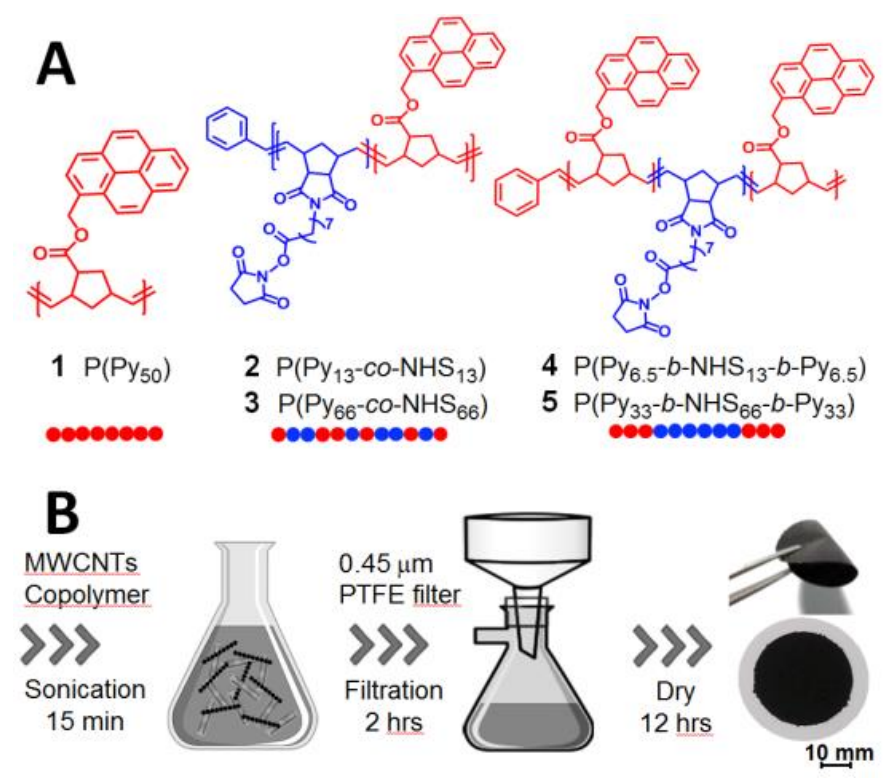

Figure 1. (A) Chemical and sequence structure of polynorbornene random and triblock (A-B-A) bifunctional copolymers used. (B) Scheme illustrating buckypaper fabrication method.

Initial experiments were investigated using polymer $\mathbf{1}$ as a model polymer to optimize the conductivity and mechanical performance of polynorbornene BP as a function of the CNT: polymer solution ratio (Figure 2). The highest conductivity of $18 \mathrm{~S} \mathrm{~cm}^{-1}$ was obtained for BP prepared with only CNTs (BP- 
CNT). This value lies between those of chemically functionalized CNT BPs reported previously. [20,23] The conductivity of BP-1 decreased linearly as the amount of polymer solution used was increased from $0 \%$ to $50 \%$, consistent with the increasing presence of an insulating or weakly conducting polymer (Figure 2A). In contrast, the tensile modulus increased by $280 \%$ to $1.9 \mathrm{GPa}$ as the amount of polymer solution used increased from $0 \%$ to $20 \%$. Increasing the polymer solution amount further from $20 \%$ to $40 \%$ resulted in a two-fold decrease in modulus to $0.9 \mathrm{GPa}$. The decrease in modulus beyond $20 \%$ highlights the importance of CNTs as the principal material for structural stability and resistance to deformation. Similar trends were observed for tensile strength (Table S1). Based on these measurements, we chose a ratio of $80 \%$ CNT: $20 \%$ polymer as the optimal method for preparation of free-standing BPs with good conductivity and improved mechanical stability. Further stress-strain curves were recorded (Figure S1) to compare the difference in mechanical properties between buckypaper prepared without and with polymer, where the optimal $80 \%$ CNT: $20 \%$ polymer ratio was used for buckypaper-polymer samples. BP-CNT without polymer exhibited a tensile modulus and strength of $0.5 \mathrm{GPa}$ and $0.9 \mathrm{MPa}$, respectively. In contrast, BP-1 exhibited a tensile modulus of 1.9 GP and tensile strength of 3.4 MPa, and BP-3 exhibited a tensile modulus of 2.3 GPa and tensile strength of 4.1 MPa. These values are comparable to literature values and clearly show a significant increase by up to a factor of 4.5 in tensile modulus and strength with incorporation of the polymer in buckypaper.[23] The increase in tensile properties is consistent with an improvement in stiffness and strength and thus mechanical stability of the buckypaper which is desirable for electrode durability. Figure 2B shows conductivity data for BPs prepared using polynorbornenes 1-5 via the optimized CNT: polymer solution ratio. As expected, BPCNT is more conductive than the polynorbornene BPs. The polynorbornene BPs have similar conductivities considering the experimental error. 

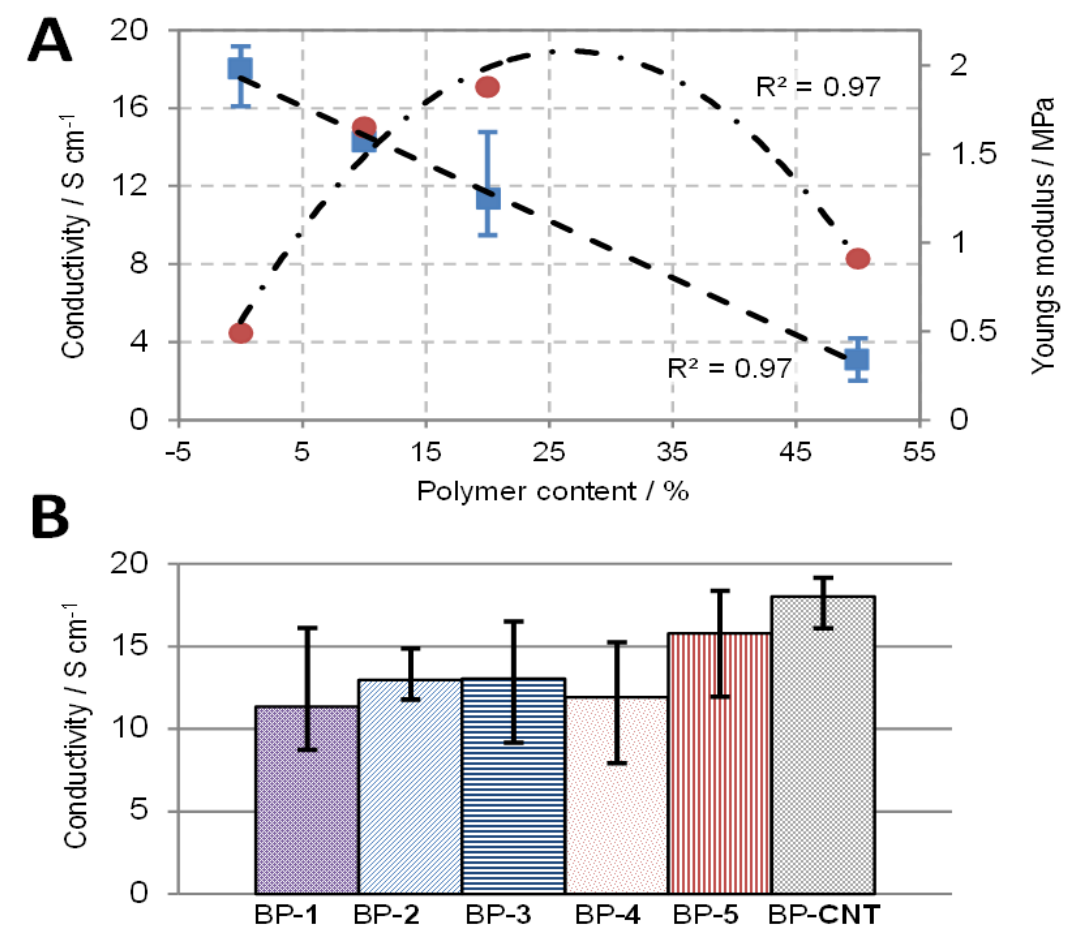

Figure 2. (A) Plot of conductivity (squares) and Young's (tensile) modulus (circles) as a function of the percentage of polymer 1 solution used during buckypaper fabrication. (B) Chart showing conductivity for polynorbornene buckypapers (BP-1 to BP-5) and CNT only buckypaper (BP-CNT).

Contact angle measurements were also obtained to shed light on the wettability of the polynorbornene materials (Figure S2). BP-1 and BP-3 have contact angles of $136 \pm 6^{\circ}$ and $122 \pm 1^{\circ}$ whereas BP-CNT exhibits a contact angle of $95 \pm 2^{\circ}$. The presence of polynorbornene therefore increases the hydrophobicity substantially to the extent that water is unlikely to be absorbed into the polynorbornene buckypapers. The aqueous impermeability is desirable for containment of electrolyte solutions in biofuel design. The increasing hydrophobicity with addition of polymer is consistent with a change in physical rather than chemical structure as the incorporation of hydrophilic ester groups (BP-3) did not increase the hydrophilicity compared to BP-1.

Next the chemical reactivity of N-hydroxysuccinmide (NHS) ester groups of BP were investigated by coupling electroactive species and estimating surface concentrations based on the cyclic voltammograms 
$(\mathrm{CVs})$ of modified surfaces. BP-1 to BP-5 were reacted with $2 \mathrm{mM}$ of 2-aminoanthraquinone (AQ) in $\mathrm{EtOH}$ to attach these groups to the surface via amide bond formation. Surface concentration data for BP1 to BP-5 is listed in Table 1. Figure 3 shows typical CVs obtained in $0.1 \mathrm{M}$ phosphate buffer (PB) pH 7 at BP-3 (Figure 3A) and BP-1 (Figure 3B) before and after modification with AQ groups. Similar CVs were obtained for the other BP electrodes (Figure S3).

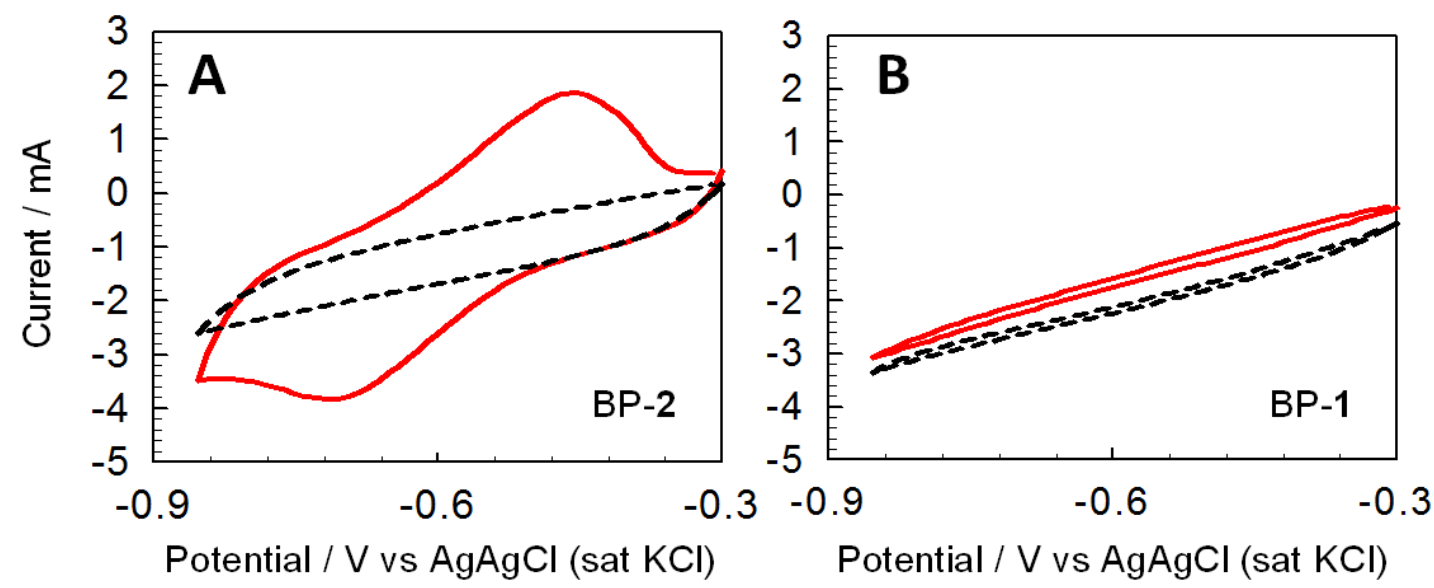

Figure 3. CVs obtained in $0.1 \mathrm{M} \mathrm{PB} \mathrm{pH} 7$ at scan rate $=20 \mathrm{mV} / \mathrm{s}$ for buckypapers (A) BP-3 and (B) BP1 before (--) and after (-) reaction with aminoanthraquinone.

The CVs obtained for BP-2 to BP-5 show well-defined redox peaks at around $E_{\mathrm{p}}=-0.58 \mathrm{~V}$ vs $\mathrm{AgAgCl}$, corresponding to the two-electron reduction of AQ groups,[24] consistent with successful coupling of electroactive AQ groups via substitution of the NHS ester. As expected for surface-immobilised redox couples, the peak currents are linearly dependent on the scan rate (Figure S4). In contrast, CVs obtained for BP-1 (no NHS ester groups) reveal ill-defined electrochemistry and no evidence for coupled electroactive AQ groups, as expected. The stability of BP-3 modified with AQ groups was subsequently investigated by repeat potential cycling over the range $0.0 \mathrm{~V}$ to $-1.1 \mathrm{~V}$ in $\mathrm{PB} \mathrm{pH} 7$. A $20 \%$ loss in signal over 10 cycles is consistent with a stable attachment (Figure S4), especially considering that the current decrease may also be due to a preceding chemical reaction such as protonation of $\mathrm{AQ}^{2-}$ to $\mathrm{AQH}_{2}$.[24] $\mathrm{It}$ 
is noted that all BP electrodes were sonicated for $1 \mathrm{~min}$ in $\mathrm{EtOH}$ prior to analysis, supporting the stable nature of the AQ attachment.

Examination of the data in Table 1 shows that larger surface concentrations of electroactive AQ groups were obtained on BP-3 and BP-5 after surface coupling. These electrodes were prepared using the longchain random and triblock polymer chains, respectively. The obtained surface concentrations of between 0.38 and $3.78 \times 10^{-8} \mathrm{~mol} \mathrm{~cm}^{-2}$ at the different electrodes are significantly greater than theoretical values for a monolayer of AQ oriented flat $\left(3.3 \times 10^{-10} \mathrm{~mol} \mathrm{~cm}^{-2}\right)$ or vertical $\left(1.6 \times 10^{-9} \mathrm{~mol} \mathrm{~cm}^{-2}\right)$ to an electrode surface[25], owing to the large surface area and porosity of the buckypaper. The larger surface concentrations obtained using long-chain polymers are attributed to improved wrapping via inter-chain interactions and accessibility of NHS ester groups within the entangled carbon nanotube network. Use of the more structurally precise triblock copolymer did not result in higher concentrations of AQ groups than the random sequence polymer of equivalent length. Precision positioning of functional groups on the polymer backbone appears, at least under the conditions employed here, less important than the length of the chain.

The length of polymer chain has a significant effect on the kinetics of the AQ electrochemistry, as shown by the differences in peak-to-peak separation $\left(\Delta E_{\mathrm{p}}\right)$ and estimated electron transfer rate constant $\left(k_{\mathrm{s}}\right)$, where larger $\Delta E_{\mathrm{p}}$ values and smaller $k_{\mathrm{s}}$ indicate slower kinetics of the immobilised AQ groups (Table 1). The BPs containing short-chain polymers showed the smallest values of $\Delta E_{\mathrm{p}}$ and $k_{\mathrm{s}}$, whereas the longchain polymer BPs showed larger values of $\Delta E_{\mathrm{p}}$ and $k_{\mathrm{s}}$. The apparent electron transfer kinetics are therefore consistently slower for BP structures comprising longer polymers. This likely reflects the increasing distance between the electrode and the terminal AQ groups and therefore increasing electron tunneling and electronic coupling distances. The effect of decreasing electron transfer rate with increasing chain length has previously been reported for electroactive groups tethered to insulating monolayers on electrodes.[26] 
Table 1. Electrochemical Data for AQ Groups Coupled to Multifunctional Buckypaper

Electrodes.

\begin{tabular}{llllll}
\hline Buckypaper & $\begin{array}{l}\text { Polymer } \\
\text { Sequence }\end{array}$ & $\begin{array}{l}\text { Polymer } \\
\text { Structure }\end{array}$ & $\begin{array}{l}\text { Surface Concentration } \\
\left(\Gamma_{\mathrm{AQ}}\right)\left(10^{-8} \mathrm{~mol} \mathrm{~cm}^{-2}\right)\end{array}$ & $\begin{array}{l}\Delta E_{p} \\
(\mathrm{mV})\end{array}$ & $\begin{array}{l}k_{s} \\
\left(\mathrm{~s}^{-1}\right)\end{array}$ \\
\hline BP-2 & Random & $\mathrm{P}\left(\mathrm{Py}_{13} \mathrm{NHS}_{13}\right)$ & $0.38 \pm 0.19(n=2)^{[\mathrm{a}]}$ & 161 & $3.38 \times 10^{-2}$ \\
BP-3 & Random & $\mathrm{P}\left(\mathrm{Py}_{66} \mathrm{NHS}_{66}\right)$ & $3.78 \pm 0.76(n=2)$ & 333 & $1.18 \times 10^{-3}$ \\
BP-4 & Triblock & $\mathrm{P}\left(\mathrm{Py}_{6.5} \mathrm{NHS}_{13} \mathrm{Py}_{6.5}\right)$ & $0.65 \pm 0.21(n=4)$ & 264 & $4.53 \times 10^{-3}$ \\
BP-5 & Triblock & $\mathrm{P}\left(\mathrm{Py}_{33} \mathrm{NHS}_{66} \mathrm{Py}_{33}\right)$ & $2.25 \pm 1.28(n=2)$ & 308 & $1.92 \times 10^{-3}$ \\
& & & & & \\
\hline
\end{tabular}

${ }^{[a]}$ Number of independent buckypaper samples analysed shown in brackets

Next the practical application of the BPs was investigated for preparation of a biocathode. Three BP electrodes: unmodified BP-1, unmodified BP-3 and BP-3 modified with AQ groups, were incubated with laccase, washed and then tested for enzyme presence and activity. Figure 4 (A-C) shows CVs recorded under argon (--) and oxygen (-) after immersion of the electrodes in laccase in $0.1 \mathrm{M} \mathrm{PB}$ pH 5 for $1 \mathrm{hr}$ at $5{ }^{\circ} \mathrm{C}$. For all electrodes, no electrocatalytic activity was observed under argon. Under oxygen, the unmodified and AQ-modified BP-3 electrodes exhibited an onset potential of $0.63 \mathrm{~V}$, closely matching the redox potential of the $\mathrm{T} 1$ center of Trametes versicolor. In both cases, the electrocatalytic reduction waves confirm direct electron transfer (DET) between the BP and laccase. In contrast, little evidence of catalytic current was observed for BP-1. The results clearly show that immobilization of laccase on BP is possible via non-covalent interaction of the enzyme with surface-bound AQ groups or via covalent reaction of the amine groups of lysine residues with surface-bound NHS ester groups. The lack of catalytic current observed at BP-1 is consistent with negligible non-specific adsorption of laccase onto the surface of polynorbornene BPs under our conditions. For quantitative assessment of catalytic performance, chronoamperometric measurements were performed (Figure 4 (D-F)). 

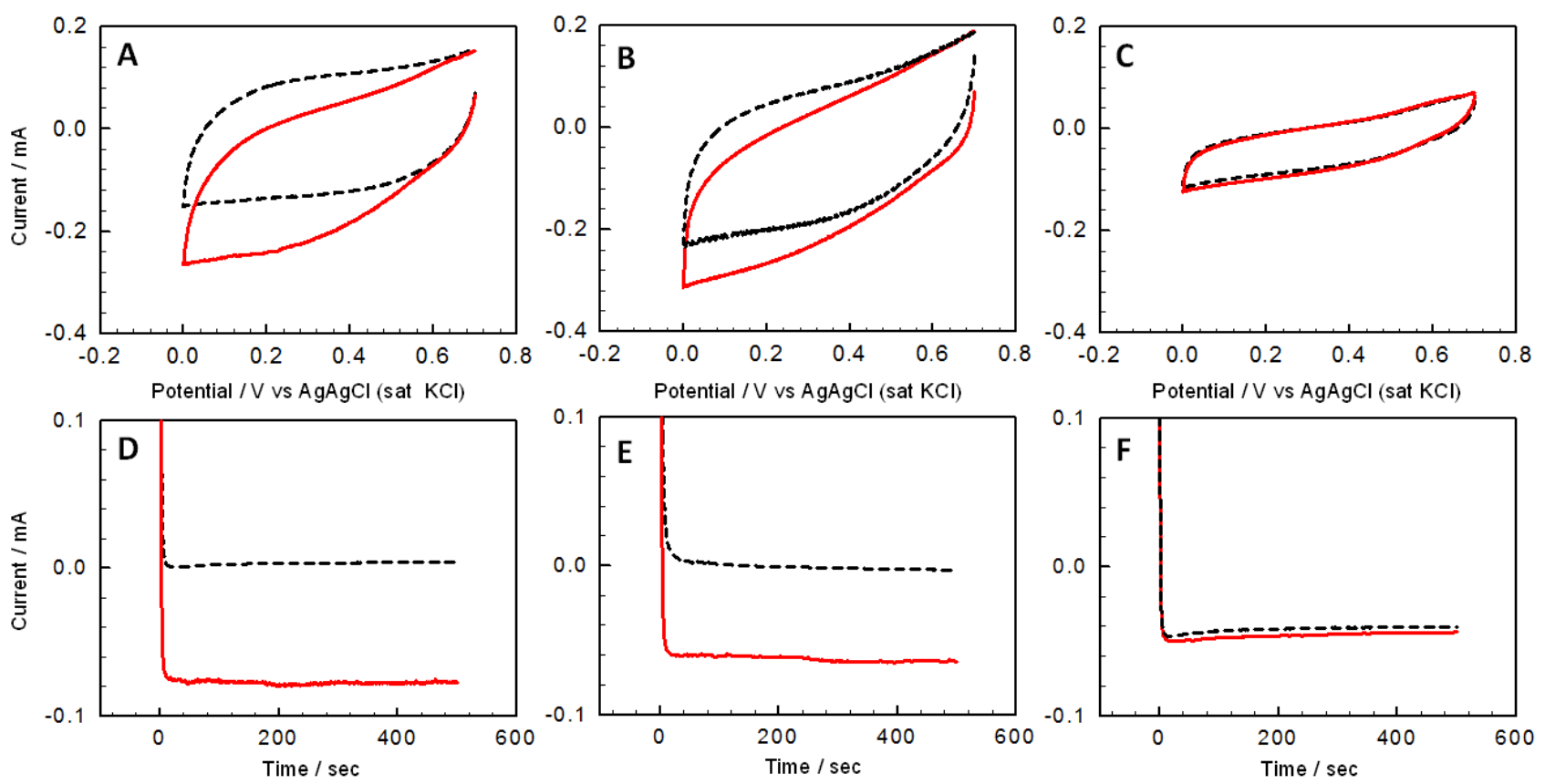

Figure 4. (A-C) CVs and (D-F) chronoamperograms obtained in $0.1 \mathrm{M} \mathrm{PB}$ pH 5 under argon (--) and under oxygen (-) for (A,D) AQ-modified BP-3, (B, E) unmodified BP-3 and (C, F) unmodified BP-1, after incubation of laccase for $1 \mathrm{hr}$. CVs recorded at scan rate $=20 \mathrm{mV} / \mathrm{s}$. Chronoamperograms recorded at $E_{\mathrm{p}}=0.25 \mathrm{~V}$ vs $\mathrm{AgAgCl}($ sat. $\mathrm{KCl})$.

The AQ-modified BP-3 electrode exhibited the highest average current density of $170 \pm 8 \mu \mathrm{A} / \mathrm{cm}^{2}(n=$ 2) in oxygen-saturated solution. The unmodified BP-3 and BP-1 electrodes exhibited average current densities of $116 \pm 30 \mu \mathrm{A} / \mathrm{cm}^{2}$ and $7 \pm 3 \mu \mathrm{A} / \mathrm{cm}^{2}$, respectively. The $32 \%$ increase in catalytic reduction of oxygen for AQ-modified BP-3 compared to unmodified BP-3 suggests the major role of anthraquinone in orienting and wiring the enzyme on the electrode surface by interaction with the hydrophobic pocket near the T1 copper site of laccase.[27] The maximum current observed here is higher than the 140 $\mu \mathrm{A} / \mathrm{cm}^{2}$ previously shown for direct oxygen reduction on anthracene-modified CNT electrodes[28] and lower than the 240-300 $\mu \mathrm{A} / \mathrm{cm}^{2}$ obtained for AQ-modified CNT electrodes.[29, 30] 
The long term stability of enzyme modified electrodes was also investigated using AQ-modified BP-3 electrodes. The BP-3 biocathode showed excellent stability with current density decreasing by $22 \%$ over the first 7 days and $47 \%$ over 24 days (Figure S5). The decrease is likely due to continual desorption of the enzyme and loss of enzyme activity over time.

\section{Conclusion}

In summary, these investigations show all the prerequisites of a global strategy to prepare versatile and robust free-standing buckypaper electrode platforms with tailored chemical functionalities. We have highlighted the possibility to obtain a high density of reactive activated ester tethers using polynorbornene copolymer-carbon nanotube buckypaper for controlled immobilization of enzymes and orienting moieties via amide bond formation for bioelectrocatalysis. Mechanical experiments confirmed an increase by a factor of up to 4.5 in both tensile modulus and tensile strength of buckypaper with the incorporation of $20 \mathrm{wt} \%$ of the random long-chain copolymer, consistent with effective incorporation and cross linking of the polymer with nanotubes via pyrene groups. Furthermore, our results demonstrate that the use of covalent coupling strategies to attach laccase to buckypaper electrodes, either directly, or indirectly via an orienting moiety, enables significantly larger catalytic currents for oxygen reduction than can be obtained when only simple physisorption is used to attach the enzyme. The general character

of the NHS ester functionality present in the polynorbornene copolymer buckypapers offers great versatility in terms of the range of enzymes, orienting groups and mediators which can be attached to the surface in future work. New functional polymers are also envisaged for preparation of bioelectrodes with different functionalities using polynorbornene chemistry as a versatile means of polymer assembly.

\section{Acknowledgements}


This work was supported by LABEX ARCANE (ANR-11-LABX-0003-01) and Chimie NanoBio ICMG. We gratefully acknowledge the technical assistance and advice of Dafni Moatsou, Pierre Sailler and Raoudha Haddad.

\section{Supporting Information}

Details of synthetic protocols and supporting characterization data available online.

\section{References}

1. Cosnier, S.; Le Goff, A.; Holzinger, M., Towards glucose biofuel cells implanted in human body for powering artificial organs: Review. Electrochem. Commun. 2014, 38, 19-23.

2. Slaughter, G.; Kulkarni, T., Enzymatic Glucose Biofuel Cell and its Application. J. Biochips Tiss. Chips 2015, 5, (111), 2153-0777.1000111.

3. Bandodkar, A. J.; Wang, J., Wearable Biofuel Cells: A Review. Electroanalysis 2016, In press, DOI: 10.1002/elan.201600019.

4. Cinquin, P.; Gondran, C.; Giroud, F.; Mazabrard, S.; Pellissier, A.; Boucher, F.; Alcaraz, J.-P.; Gorgy, K.; Lenouvel, F.; Mathé, S.; Porcu, P.; Cosnier, S., A Glucose BioFuel Cell Implanted in Rats. PLoS ONE 2010, 5, (5), e10476.

5. Halámková, L.; Halámek, J.; Bocharova, V.; Szczupak, A.; Alfonta, L.; Katz, E., Implanted Biofuel Cell Operating in a Living Snail. J. Am. Chem. Soc. 2012, 134, (11), 5040-5043.

6. Calabrese Barton, S.; Gallaway, J.; Atanassov, P., Enzymatic Biofuel Cells for Implantable and Microscale Devices. Chem. Rev. 2004, 104, (10), 4867-4886.

7. Rasmussen, M.; Abdellaoui, S.; Minteer, S. D., Enzymatic biofuel cells: 30 years of critical advancements. Biosens. Bioelectron. 2016, 76, 91-102 
8. Zebda, A.; Gondran, C.; Le Goff, A.; Holzinger, M.; Cinquin, P.; Cosnier, S., Mediatorless highpower glucose biofuel cells based on compressed carbon nanotube-enzyme electrodes. Nat. Commun. 2011, 2, 370 .

9. Cosnier, S.; Holzinger, M.; Le Goff, A., Recent advances in Carbon Nanotube based Enzymatic Fuel Cells. Front. Bioeng. Biotechnol. 2014, 2.

10. Gentil, S.; Serre, D.; Philouze, C.; Holzinger, M.; Thomas, F.; Le Goff, A., Electrocatalytic O2 Reduction at a Bio-inspired Mononuclear Copper Phenolato Complex Immobilized on a Carbon Nanotube Electrode. Angew. Chem. Int. Ed. 2016, 55, 2517-2520.

11. Holmberg, S.; Rodriguez-Delgado, M.; Milton, R. D.; Ornelas-Soto, N.; Minteer, S. D.; Parra, R.; Madou, M. J., Bioelectrochemical Study of Thermostable Pycnoporus sanguineus CS43 Laccase Bioelectrodes Based on Pyrolytic Carbon Nanofibers for Bioelectrocatalytic O-2 Reduction. ACS Catal. 2015, 5, (12), 7507-7518.

12. Bandodkar, A. J.; Jeerapan, I.; You, J.-M.; Nuñez-Flores, R.; Wang, J., Highly Stretchable FullyPrinted CNT-Based Electrochemical Sensors and Biofuel Cells: Combining Intrinsic and DesignInduced Stretchability. Nano Lett. 2016, 16, (1), 721-727.

13. Ivnitski, D.; Branch, B.; Atanassov, P.; Apblett, C., Glucose oxidase anode for biofuel cell based on direct electron transfer. Electrochem. Commun. 2006, 8, (8), 1204-1210.

14. Elouarzaki, K.; Bourourou, M.; Holzinger, M.; Le Goff, A.; Marks, R. S.; Cosnier, S., Freestanding HRP-GOx redox buckypaper as an oxygen-reducing biocathode for biofuel cell applications. Energy. Environ. Sci. 2015, 8, (7), 2069-2074.

15. Cosnier, S.; Haddad, R.; Moatsou, D.; O’Reilly, R. K., Biofunctionalizable flexible bucky paper by combination of multi-walled carbon nanotubes and polynorbornene-pyrene - Application to the bioelectrocatalytic reduction of oxygen. Carbon 2015, 93, 713-718.

16. Szczupak, A.; Halamek, J.; Halamkova, L.; Bocharova, V.; Alfonta, L.; Katz, E., Living battery - biofuel cells operating in vivo in clams. Energy. Environ. Sci. 2012, 5, (10), 8891-8895. 
17. Hussein, L.; Rubenwolf, S.; von Stetten, F.; Urban, G.; Zengerle, R.; Krueger, M.; Kerzenmacher, S., A highly efficient buckypaper-based electrode material for mediatorless laccase-catalyzed dioxygen reduction. Biosens. Bioelectron. 2011, 26, (10), 4133-4138.

18. Narváez Villarrubia, C. W.; Lau, C.; Ciniciato, G. P. M. K.; Garcia, S. O.; Sibbett, S. S.; Petsev, D. N.; Babanova, S.; Gupta, G.; Atanassov, P., Practical electricity generation from a paper based biofuel cell powered by glucose in ubiquitous liquids. Electrochem. Commun. 2014, 45, 44-47.

19. Ahmadalinezhad, A.; Wu, G. S.; Chen, A. C., Mediator-free electrochemical biosensor based on buckypaper with enhanced stability and sensitivity for glucose detection. Biosens. Bioelectron. 2011, 30, (1), 287-293.

20. Bourourou, M.; Elouarzaki, K.; Holzinger, M.; Agnes, C.; Le Goff, A.; Reverdy-Bruas, N.; Chaussy, D.; Party, M.; Maaref, A.; Cosnier, S., Freestanding redox buckypaper electrodes from multiwall carbon nanotubes for bioelectrocatalytic oxygen reduction via mediated electron transfer. Chem. Sci 2014, 5, (7), 2885-2888.

21. Bunte, C.; Hussein, L.; Urban, G. A., Performance of non-compartmentalized enzymatic biofuel cell based on buckypaper cathode and ferrocene-containing redox polymer anode. J. Power Sources 2014, 247, 579-586.

22. Lau, C.; Moehlenbrock, M. J.; Arechederra, R. L.; Falase, A.; Garcia, K.; Rincon, R.; Minteer, S. D.; Banta, S.; Gupta, G.; Babanova, S.; Atanassov, P., Paper based biofuel cells: Incorporating enzymatic cascades for ethanol and methanol oxidation. Int. J. Hydrogen Energy 2015, 40, (42), 14661-14666.

23. Trakakis, G.; Tasis, D.; Parthenios, J.; Galiotis, C.; Papagelis, K., Structural Properties of Chemically Functionalized Carbon Nanotube Thin Films. Materials 2013, 6, (6), 2360-2371.

24. Haque, M. A.; Rahman, M. M.; Susan, M. A. B. H., Aqueous Electrochemistry of Anthraquinone and Its Correlation with the Dissolved States of a Cationic Surfactant. J. Solution. Chem. 2011, 40, (5), 861-875. 
25. Ghanem, M. A.; Chretien, J.-M.; Pinczewska, A.; Kilburn, J. D.; Bartlett, P. N., Covalent modification of glassy carbon surface with organic redox probes through diamine linkers using electrochemical and solid-phase synthesis methodologies. J. Mater. Chem. 2008, 18, (41), 4917-4927.

26. Liu, B.; Bard, A. J.; Mirkin, M. V.; Creager, S. E., Electron Transfer at Self-Assembled Monolayers Measured by Scanning Electrochemical Microscopy. J. Am. Chem. Soc. 2004, 126, (5), 1485-1492.

27. Blanford, C. F.; Heath, R. S.; Armstrong, F. A., A stable electrode for high-potential, electrocatalytic $\mathrm{O} 2$ reduction based on rational attachment of a blue copper oxidase to a graphite surface. Chem. Commun. 2007, (17), 1710-1712.

28. Meredith, M. T.; Minson, M.; Hickey, D.; Artyushkova, K.; Glatzhofer, D. T.; Minteer, S. D., Anthracene-Modified Multi-Walled Carbon Nanotubes as Direct Electron Transfer Scaffolds for Enzymatic Oxygen Reduction. ACS Catal. 2011, 1, (12), 1683-1690.

29. Bourourou, M.; Elouarzaki, K.; Lalaoui, N.; Agnès, C.; Le Goff, A.; Holzinger, M.; Maaref, A.; Cosnier, S., Supramolecular Immobilization of Laccase on Carbon Nanotube Electrodes Functionalized with (Methylpyrenylaminomethyl)anthraquinone for Direct Electron Reduction of Oxygen. Chem. Eur. J. 2013, 19, (28), 9371-9375.

30. Stolarczyk, K.; Sepelowska, M.; Lyp, D.; Żelechowska, K.; Biernat, J. F.; Rogalski, J.; Farmer, K. D.; Roberts, K. N.; Bilewicz, R., Hybrid biobattery based on arylated carbon nanotubes and laccase. Bioelectrochemistry 2012, 87, 154-163. 